\title{
Pemanfaatan open access Jurnal Borneo Administrator melalui pengukuran kepuasan pembaca di Lembaga Administrasi Negara
}

\author{
Dewi Sartika1, Ricky Noor Permadi2 \\ 1,2Pusat Pelatihan dan Pengembangan dan Kajian Desentralisasi dan Otonomi Daerah \\ Jl. HM Ardans SH (Ring Road III), Samarinda, Kalimantan Timur, 75131 \\ E-mail: ${ }^{1}$ dewi.sartika@lan.go.id, 2ricky.permadi@lan.go.id
}

Received: February 2020; Accepted: October 2020; Published: December 2020

\begin{abstract}
Open Access Journal (OAJ) is a journal publication that contains articles in full text and user's can be accessed and used free of charge. The purpose of this study was to determine the extent to which open access was used in the Borneo Administrator Journal (JBA) by measuring reader satisfaction. The research method used was a descriptive quantitative approach. The data collection used a survey method and a data analysis technique used a simple descriptive statistical method. This research has eight research questions, namely the level of user's satisfaction with access and download facilities, Kemenristek/Dikti accreditation, language, benefit for the profession and career advancement, number of articles and columns, overall format and content, issued quarterly ( $3 x$ a year), and services provided by JBA managers. The research data analysis has the three highest indicators were published every quarter ( $3 x$ a year), the format and content as a whole, and were beneficial for professional and career advancement. The lowest score indicators but still in the satisfied category were download facilities, language, and the number of articles and columns. In conclusion, the overall level of reader satisfaction is in the satisfied category. The implementation of open access in the Borneo Administrator Journal is basically to support the development and dissemination of knowledge.
\end{abstract}

Keywords: Open access journal; Electronic publications; Borneo Administrator Journal; National Institute Of Public Administration

\begin{abstract}
Abstrak
Open Access Journal (OAJ) atau jurnal dengan akses terbuka ialah suatu terbitan jurnal yang berisi artikel secara halaman penuh (full text), dapat diakses, dan dimanfaatkan secara gratis oleh pengguna. Tujuan penelitian ini adalah untuk mengetahui sejauh mana pemanfaatan open access pada Jurnal Borneo Administrator (JBA) melalui pengukuran kepuasan pada pembaca. Metode penelitian yang digunakan adalah pendekatan kuantitatif deskriptif. Adapun teknik pengumpulan data menggunakan metode survei dan teknik analisis data menggunakan metode statistik deskriptif sederhana. Hasil penelitian menunjukkan bahwa pengukuran kepuasan pembaca menggunakan delapan pertanyaan penelitian yang terdiri dari tingkat kepuasan pengguna pada indikator fasilitas akses dan unduhan, akreditasi Kemenristek/Dikti, bahasa, kemanfaatan terhadap profesi dan peningkatan karier, jumlah artikel dan kolom, format dan konten keseluruhan, terbitan jurnal selama triwulan ( $3 \mathrm{x}$ setahun), dan pelayanan yang diberikan pengelola JBA. Data penelitian yang dianalisis memiliki tiga indikator tertinggi, yaitu pada terbitan jurnal triwulan ( $3 x$ setahun), format dan konten secara keseluruhan, dan kemanfaatan terhadap profesi dan peningkatan karier. Indikator dengan nilai terendah terdapat dalam kategori puas pada indikator fasilitas unduhan, bahasa, jumlah artikel dan kolom. Maka dapat disimpulkan bahwa tingkat kepuasan pembaca secara keseluruhan berada pada kategori puas. Adapun penerapan open access pada Jurnal Borneo Administrator pada dasarnya untuk mendukung perkembangan dan diseminasi ilmu pengetahuan.
\end{abstract}

Kata Kunci: Jurnal akses terbuka; Publikasi elektronik; Jurnal Borneo Administrator; Lembaga Administrasi Negara 


\section{PENDAHULUAN}

Teknologi digital telah menciptakan revolusi yang sangat besar, tidak terkecuali dalam dunia karya tulis ilmiah. Karya tulis ilmiah telah mengalami pergeseran dari teks berupa tinta kertas ke digital. Hal ini memungkinkan suatu karya tulis ilmiah dapat digunakan dan dimanfaatkan dengan mudah oleh berbagai kalangan. Teknologi telah menciptakan dampak besar di dunia pendidikan.

Salah satu dampaknya ialah fenomena Open Access (OA) yang berkembang seiring digunakannya internet di dunia. Istilah Open Access secara formal baru dipublikasikan pada 2002 pada acara Budapest Open Access Initiative. Open access $(O A)$ didefinisikan sebagai sumber referensi literatur berbentuk digital, yang dapat diakses secara daring (online), bebas biaya, dan bebas dari pembatasan hak cipta serta lisensi (Sauber, 2013). Perpustakaan di Indonesia, menerapkan open access dalam online journal yang secara langsung didukung melalui Peraturan Menteri Riset, Teknologi, dan Pendidikan Tinggi Republik Indonesia Nomor 9 Tahun 2018 Tentang Akreditasi Jurnal Ilmiah (2018). Peraturan tersebut mensyaratkan bahwa jurnal terbitan yang akan diakreditasi harus terbit dalam bentuk online. Hal ini tentu saja semakin mendorong bagi penerbit jurnal untuk cepat melakukan migrasi dari jurnal cetak ke online journal.

Open access berawal dari deklarasi Budapest Open Access pada tanggal 14-15 Februari 2002 di Hungaria. Kehadiran open access telah menarik berbagai lembaga pendidikan, pelatihan, dan perpustakaan berlomba-lomba membangun portal digital untuk diseminasi publikasi karya tulis ilmiah, berupa jurnal akses terbuka atau disebut Open Access Journal (OAJ) (Yudhanto \& Nashihuddin, 2017). Gerakan open access sendiri ditujukan untuk melawan kapitalisme ilmu pengetahuan. Para penerbit tersebut biasanya menerbitkan publikasi yang berorientasi pada keuntungan semata (Prasetyawan, 2017). Adapun model pendanaan proses open access selama ini tidak membebankan biaya dari penulis dan lembaga saat mengakses informasi. Pada dasarnya, open access merupakan alat dalam mencapai diseminasi informasi ilmiah.

Jurnal yang bersifat open access telah mengalami perkembangan jauh lebih cepat dibandingkan jurnal berlangganan (non open access) namun jurnal open access jumlahnya masih kurang dari 12\% dalam daftar Scopus (Solomon, Laakso, \& Björk, 2013). Bahkan Linuwih (2015) dalam penelitiannya menyebutkan bahwa dosen cenderung menggunakan jurnal ilmiah di Universitas Airlangga untuk memanfaatkan jurnal elektronik daripada jurnal cetak karena jurnal elektronik lebih mudah diakses. Online journal yang dirancang open access merupakan salah satu perangkat lunak alternatif untuk publikasi karya tulis ilmiah. Keberadaan open access telah mendorong ketersediaan artikel ilmiah secara bebas dan luas bagi pembaca atau bahan penelitian. Open access sendiri telah menghasilkan produk artikel ilmiah yang cenderung lebih murah dan mudah sehingga dapat tersedia bagi pembaca (Lewis, 2012).

Jurnal berbasiskan open access dalam perkembangannya memiliki pertumbuhan jauh lebih cepat dibandingkan jurnal berlangganan atau berbayar. Maka kegiatan open access diharapkan mampu melakukan akselerasi diseminasi informasi, memperkaya bahan penelitian, dan menghapus batas dalam 
perkembangan ilmu pengetahuan. Sauber (2013) melakukan identifikasi literatur yang termasuk dalam kategori open access, di antaranya digital, online, gratis, dan bebas dari sebagian besar pembatasan hak cipta dan lisensi. Semua kategori literatur open access ini membantu pengguna mengakses karya ilmiah lebih mudah tanpa terhalang copyright.

Karya ilmiah berbasis open access pun membantu pengguna membaca, mengutip, mengunduh, mendistribusikan, mencetak, dan menggunakan karya ilmiah untuk berbagai keperluan yang tidak melanggar hukum. Pengguna mengakses karya ilmiah secara legal dan tanpa menghadapi hambatan finansial merupakan suatu prakarsa bersama oleh penggiat gerakan open access. Menurut Laakso and Björk (2016), jurnal berbasis open access sesuai pola penerbitan terbagi dua jenis, yaitu gold open access dan green open access. Gold open access merupakan penerbit jurnal yang menyediakan artikel ilmiah secara langsung dan bebas biaya untuk diakses pengguna. Walaupun demikian, penerbit jurnal tetap menarik biaya pemrosesan artikel hingga terbit pada pengguna, contohnya penulis, pendana riset, atau instansi penulis, yang ingin menerbitkan karya ilmiahnya. Adapun istilah kedua adalah green open access, yakni penulis artikel jurnal mengunggah artikelnya ke dalam website pribadi ditujukan bagi pengguna yang tidak memiliki hak akses untuk berlangganan jurnal.

Open Access Journal (OAJ) atau jurnal dengan akses terbuka merupakan suatu terbitan jurnal yang berisikan artikel dengan halaman penuh dan diakses tanpa dipungut biaya melalui media internet. Pengguna dengan memanfaatkan sistem $O A J$ dapat bebas mengunduh, membaca, bahkan mencetak jurnal. Selain itu, pengguna pun terbantu sekali dalam mengumpulkan bahan untuk penelitian yang tersebar banyak di OAJ. Selama ini, publikasi karya ilmiah mengedepankan aspek komersial dan memiliki akses yang begitu mahal sehingga membatasi kebebasan, sirkulasi, dan penggunaan hasil penelitian oleh institusi, peneliti, dan akademisi. Hal tersebut tentu sangat berlawanan dengan gerakan open access yang lumrah berlaku di dunia publikasi karya tulis ilmiah.

Purwadi and Irwansyah (2020) pun menuturkan bahwa teknologi membantu dunia penerbitan jurnal untuk dapat digunakan masyarakat luas, terutama generasi milenial yang sudah akrab dengan teknologi. Teknologi memudahkan pengguna mengakses data dan informasi karya ilmiah sedangkan dari sisi diseminasi informasi, teknologi membuat karya ilmiah cepat, efisien, dan efektif. Selain itu, teknologi dalam $O A J$ membantu pengguna dalam menggunakan karya ilmiah tanpa mengganggu hak cipta (copyright). Sauber (2013) menyatakan bahwa hak cipta sebagai penghalang akses yang signifikan terhadap suatu karya tulis ilmiah. Maka penulis cukup sulit melakukan sitasi terhadap karya tulis ilmiah tersebut. Hal ini memiliki dampak sulitnya karya tulis untuk dinilai, misalnya untuk menerjemahkan, menyalin teks, dan mengutip yang harus memerlukan izin dari pemegang hak cipta. Open access berupaya meminimalkan hambatan izin suatu hak cipta dan memberikan solusi untuk masalah akses terbatas terhadap hasil penelitian yang didanai oleh publik/pemerintah.

Gerakan open access muncul sebagai reaksi terhadap kondisi di atas, yaitu gerakan ini berusaha menyediakan 
alternatif sumber informasi ilmiah agar dapat diakses dan digunakan secara bebas oleh pengguna. Adapun indikator keberhasilan sebuah artikel ilmiah adalah jumlah kutipan yang ditujukan untuk artikel tersebut. Maka gagasan artikel open access akan mendapatkan lebih banyak kutipan daripada artikel non open access. Hal ini memungkinkan jumlah pembaca lebih besar mengakses artikel ilmiah dan berpotensi menambah kutipan. Apalagi artikel ilmiah dengan open access secara konsisten akan meraih serangkaian kutipan yang lebih beragam daripada artikel non open access (Young \& Brandes, 2020).

Pengguna yang banyak mengutip sitasi dari penulis lain akan menambah analisis karya ilmiahnya. Open access telah membantu meningkatkan sitasi rujukan karya ilmiah. Maka open access sebagai suatu alat dalam meminimalkan plagiarisme (Suwarno, 2014). Informasi dan data hasil penelitian dalam open access akan dapat tersebarluaskan, tidak hanya berhenti pada perpustakaan atau penerbit jurnal saja. Akses informasi yang meluas ini dapat membantu peneliti untuk melihat apakah karya ilmiah yang dibacanya merupakan hasil plagiarisme atau bukan. Tetapi di sisi lain terdapat pula pihak yang berpendapat bahwa open access bisa memudahkan kegiatan plagiarisme (Suwarno, 2014).

Perkembangan open access di Indonesia sudah mulai masif terutama dalam aplikasi online journal di berbagai bidang dan institusi. Gerakan open access sangat diperlukan untuk memudahkan pengguna mendapatkan informasi. Sesuai pelbagai fenomena yang terjadi, maka diseminasi ilmu pengetahuan dapat dipercepat sehingga mampu memacu ilmu pengetahuan baru dan penguatan teori- teori yang ada (Prasetyawan, 2017). Penerbitan jurnal berbasis open access sendiri didorong oleh dua hal utama, yakni tingginya harga jurnal dan pesatnya perkembangan teknologi informasi (Kiramang, 2017). Sekarang jurnal makin mudah diakses oleh pengguna di seluruh dunia tanpa ada tarif biaya dan format perangkat lunak yang ramah digunakan oleh semua pengguna.

Adapun bagi penerbit jurnal, kegiatan pengelolaan dan penerbitan dapat memanfaatkan perangkat lunak Open Journal System (OJS) dari Public Knowledge Project (PKP). Open journal system merupakan sebuah aplikasi yang diperuntukan untuk pengelolaan dan penerbitan jurnal ilmiah yang dioperasikan secara fleksibel dan gratis, terdiri dari fasilitas submission, peer review, editing, publishing, dan lainnya (Lukman, Marlina, Keumalasari, \& Siagian, 2012). Open journal system juga memiliki aksesibilitas jurnal yang lebih luas sehingga dapat meningkatkan sitasi, impact factor, serta terhubung dengan berbagai mesin pencari sehingga dapat memudahkan dalam proses identifikasi pencarian artikel. Selain itu, model perangkat lunak yang sering digunakan dalam mengembangkan online journal atau electronic publishing misalnya Open Journal System, DPubS, ePublishing Toolkit, GAPworks, Hypejournal, OpenACS, SOPS, TOPAZ, Scopemed, dan lainya.

Pengguna yang sering menggunakan online journal membuat perkembangannya di Indonesia cukup pesat ditambah sejak dikeluarkannya peraturan bagi mahasiswa/mahasiswi program Sarjana (S-1), Magister (S-2), dan doktor (S-3) wajib menghasilkan artikel yang terbit pada jurnal ilmiah. Walaupun demikian, penulis, editor dan mitra bestari dalam 
implementasi pengelolaan jurnal masih mengalami kesulitan. Secara tidak langsung penggunaan open journal system masih menyisakan beberapa permasalahan, yaitu pengguna jurnal diharuskan memiliki pengetahuan terkait dengan online journal (Wibowo, 2019).

Kendala lainnya dalam implementasi open journal system adalah manajemen penerbitan secara elektronik belum sepenuhnya dilakukan penerbit, penulis, editor, maupun mitra bestari. Kata lain, penerbitan jurnal elektronik di Indonesia sebagian besar hanya sebatas alih media jurnal cetak ke online (Lukman et al., 2012). Padahal untuk mendapatkan akreditasi dari Kementerian Riset dan Teknologi/Direktorat Jenderal Pendidikan Tinggi (Kemenristek/Dikti), suatu jurnal ilmiah harus menggunakan aplikasi penerbitan online journal.

Jurnal berbasis open access di Indonesia dapat dipublikasikan oleh berbagai perguruan tinggi, kementerian, lembaga pemerintah non kementerian, lembaga penelitian dan pengembangan, instansi pemerintah, maupun perusahaan swasta atau badan usaha. Lembaga Administrasi Negara (LAN) merupakan salah satu lembaga tinggi negara non kementerian yang juga memiliki publikasi jurnal ilmiah berbasiskan online journal bernama Jurnal Borneo Administrator (JBA). Sesuai perkembangannya, jurnal ini secara stabil mengoperasikan open journal system pada 2015-2016 dan telah terindeks Directory of Open Access (DOAJ). Maka seluruh artikel yang telah terbit di Jurnal Borneo Administrator bersifat open access dan dapat dimanfaatkan kalangan luas.

Jurnal Borneo Administrator pada mulanya terbit cetak. Pada akhir 2013, Jurnal Borneo Administrator bersiap melakukan transformasi ke jurnal online untuk mengikuti perkembangan zaman yang mengarah pada pemanfaatan Open Journal System. Berbagai hal telah dipersiapkan demi mencapai penerbitan secara online, mulai dari instalasi perangkat lunak Open Journal System, penentuan domain dan hosting, kelengkapan menu, hingga alur proses pengelolaan jurnal online. Proses transformasi penerapan Open Journal System secara stabil membutuhkan waktu yang tidak sebentar karena proses pengelolaan jurnal online berbeda dengan jurnal cetak.

Maka sejak 2015-2016, Jurnal Borneo Administrator telah mengoperasikan Open Journal System secara stabil dengan memanfaatkan sistem Open Journal System versi 3.1. Meskipun pengelolaannya sendiri masih menggunakan metode manual dan elektronik. Selanjutnya manajemen Jurnal Borneo Administrator di 2017 secara penuh telah menggunakan Open Journal System dan berhasil sebagai member of CrossRef untuk memperoleh Digital Object Identifier (DOI) untuk setiap artikel yang diterbitkan.

Jurnal Borneo Administrator pun pada 2018 berhasil memperoleh akreditasi jurnal nasional melalui aplikasi ARJUNA Kemenristek/Dikti dengan peringkat 2 (SINTA 2) Nomor 21/E/KPT/2018 tertanggal 9 Juli 2018. Hingga kini, Jurnal Borneo Administrator telah berhasil mencatatkan namanya di berbagai daftar jurnal nasional maupun internasional bereputasi menengah seperti DOAJ dan Index Copernicus. Secara berkelanjutan, Jurnal Borneo Administrator dikelola Tim Peneliti dari Pusat Pelatihan dan Pengembangan dan Kajian Desentralisasi dan Otonomi Daerah (Puslatbang KDOD). Tidak bisa dipungkiri bahwa Jurnal Borneo Administrator setelah 
mendapatkan akreditasi oleh Kemenristek/Dikti, terindeks di DOAJ, dan Index Copernicus tidak mengalami kekurangan naskah untuk diterbitkan.

Jurnal Borneo Administrator merupakan jurnal terbitan berkala yang didedikasikan untuk menerbitkan dan menyebarluaskan hasil penelitian dan pengembangan di bidang administrasi negara. Jurnal Borneo Administrator konsisten terbit 3 kali dalam satu tahun yakni di bulan April, Agustus, dan Desember dengan menerbitkan 5 artikel dan mengalami penambahan 1 artikel menjadi 6 artikel mulai dari Volume 15 Nomor 1 Tahun 2019. Jurnal ini memiliki topik yang mencakup isu bidang Administrasi Negara, seperti kebijakan publik, manajemen sektor publik, birokrasi, pelayanan publik, dan inovasi sektor publik. Pengelola tim jurnal akan melakukan uji plagiarisme menggunakan perangkat lunak plagscan.com dan turnitin.com pada setiap artikel yang masuk ke dalam online journal systems. Hal ini dilakukan untuk meminimalkan kasus plagiarisme dalam penulisan karya tulis ilmiah.

Untuk itu, peneliti tertarik meneliti Jurnal Borneo Administrator karena beberapa alasan. Pertama, penelitian tentang kemanfaatan jurnal dan evaluasi diri pengelolaan jurnal masih minim. Kedua, penelitian ini berfungsi mengukur kepuasan pengguna pelayanan jurnal open access dalam lingkup ilmu administrasi negara. Ketiga, penelitian ini memiliki fokus penelitian pada kategori kepuasan pengguna pelayanan, di antaranya kemanfaatan jurnal terhadap profesi/karir dan kepuasan terhadap fasilitas akses dan unduhan. Dengan demikian, penelitian ini dapat mengetahui pemanfaatan open access
Jurnal Borneo Administrator melalui pengukuran kepuasan pembaca.

\section{METODE PENELITIAN}

Penelitian ini menggunakan metode penelitian kuantitatif deskriptif untuk mengekplorasi, menggambarkan topik dan tujuan penelitian melalui pengukuran kemanfaatan dan kepuasan pembaca (kualitas) jurnal publikasi open acces pada Lembaga Administrasi Negara. Peneliti dalam pengumpulan data menggunakan metode survei karena secara umum metode ini dilakukan pada riset kuantitatif bidang manajemen dan administrasi negara. Bentuk survei yang digunakan berupa survei melalui telepon (tele survei) dan email dengan melampirkan formulir survei yang dikirim kepada responden secara langsung (field survey).

Responden dalam penelitian ini adalah pengguna dari kelompok pembaca, penulis, dan mitra bestari (reviewer) yang telah terdaftar di website jurnal selama bulan Oktober hingga November 2019. Pengguna mengisi kuesioner sebagai respons balik survei yang berjumlah 33 orang. Adapun peneliti menggunakan metode sampling purposive sampling yang ditujukan kepada setiap pengunjung website yang memanfaatkan website dan bersedia memberikan respons balik. Sesuai hasil data, menunjukkan bahwa kelompok utama responden sebagai pengguna jurnal berasal dari kalangan akademisi.

Adapun karakteristik dari 33 responden tersebut terdiri dari unsur profesi peneliti sebanyak 10 orang responden, dosen sebanyak 7 orang responden, pustakawan sebanyak 2 responden, mahasiswa 2 orang responden, dan profesi lainnya sekitar 12 responden. Peneliti memilih responden sesuai keaktifan responden menggunakan 
pelayanan pengelolaan open journal system yang diberikan pengelola Jurnal Borneo Administrator. Peneliti dalam melakukan analisa data hasil survei menggunakan analisis statistik deskriptif. Ada 8 indikator sebagai fokus dalam pengukuran tingkat kepuasan pembaca, di antaranya fasilitas akses dan unduhan, akreditasi Kemenristek/Dikti, bahasa yang digunakan, kemanfaatan terhadap profesi dan peningkatan karier, jumlah artikel dan kolom, format dan konten keseluruhan, terbit triwulan (3x setahun), dan pelayanan yang diberikan pengelola Jurnal Borneo Administrator (JBA).

\section{HASIL DAN PEMBAHASAN}

Berdasarkan teori yang dikemukakan Laakso and Björk (2016), jurnal open access dilihat dari pola penerbitan terbagi dua jenis, yaitu gold open access dan green open access. Gold open access merupakan penerbit jurnal yang menyediakan artikel ilmiah secara langsung dan tidak ada penarifan biaya. Istilah kedua adalah green open access yang membahas mengenai penulis artikel jurnal yang mengunggah artikelnya ke dalam website pribadi agar dibaca oleh pengguna yang tidak memiliki hak akses untuk berlangganan jurnal.

Maka sesuai teori Laakso and Björk (2016), Jurnal Borneo Administrator telah menerapkan jurnal dengan jenis gold open access. Artikel Jurnal Borneo Administrator dapat diakses dan diunduh secara gratis bagi pembaca melalui http://www.samarinda.lan.go.id/jba/ind ex.php/jba. Secara keseluruhan, jurnal ini tidak membebankan biaya dalam pemrosesan artikel mulai dari proses naskah masuk (submit) hingga terbit (publish).

Jurnal harus secara konsisten menerbitkan karya ilmiah. Hal ini bergantung pada pelayanan yang diberikan pengelola jurnal. Maka pengelola Jurnal harus selalu meningkatkan pelayanan kepuasan pengguna jurnal yang terdiri dari, kelompok pembaca, penulis, editor, dan mitra bestari (reviewer). Kelompok ini merupakan tokoh penting dalam menentukan keberhasilan suatu organisasi dan khususnya memberikan dampak terhadap perilaku untuk menggunakan kembali produk/pelayanan yang dimiliki oleh organisasi (Al-Ali, Bazin, \& Shamsuddin, 2015). Adapun pengukuran kualitas suatu pelayanan jurnal penting untuk dilakukan dikarenakan berkaitan dengan pertumbuhan dan perkembangan pelayanan tersebut.

Berdasarkan hasil penelitian ini, terdapat 33 responden terdiri dari unsur profesi peneliti sebanyak 10 orang, dosen sebanyak 7 orang, pustakawan sebanyak 2 , mahasiswa 2 orang, dan profesi lainnya sekitar 12 orang. Data ini menunjukkan bahwa kelompok utama responden sebagai pengguna jurnal berasal dari kalangan akademisi. Responden dari total 33 orang terdapat $9.1 \%$ responden yang berpartisipasi sebagai pembaca dan pengulas (reviewer), 3\% responden sebagai pembaca dan penulis bersama dengan pengulas (reviewer), $18.2 \%$ responden sebagai pembaca dan penulis. Sisa responden terbesar dari website jurnal saat browsing yakni sebanyak $46.4 \%$ responden. Selain itu, sekitar $30.4 \%$ responden menyatakan bahwa mengetahui dan mendengar tentang Jurnal Borneo Administrator dari teman atau kolega. Adapun responden $8.9 \%$ mengetahui internet dan sekitar $14.3 \%$ responden lainnya mengetahui website dari himpunan/organisasi profesi. Hasil ini ternyata sama dengan penelitian Thaotip 
and Nimnoi (2013), bahwa sebagian besar responden mengetahui jurnal melalui website, teman, atau kolega. Jurnal Borneo Administrator pun dikenal pengguna melalui website, rekomendasi teman, dan kolega.

Adapun mayoritas pengguna Jurnal Borneo Administrator mengetahui informasi tentang jurnal melalui website pada saat browsing. Pihak pengelola Jurnal Borneo Administrator membentuk tim promosi yang memiliki tugas memperkenalkan Jurnal Borneo Administrator kepada pembaca dan penulis potensial melalui jejaring media sosial, seperti Facebook, Instagram atau website. Media sosial adalah media yang dapat diberdayakan oleh individu maupun korporasi untuk berbagi informasi maupun saling melakukan interaksi secara langsung antar pengguna lainnya (Cakranegara \& Susilowati, 2017). Penggunaan media sosial merupakan salah satu metode efektif dalam mempromosikan maupun menyebarkan hasil penelitian agar dapat dijangkau khalayak luas. Tim promosi Jurnal Borneo Administrator pun membuat poster/flyer bertajuk "call for paper" dalam bentuk cetak untuk diberikan kepada stakeholder atau penulis potensial. Penggunaan poster/flyer dapat membantu dalam memberitahukan informasi tentang Jurnal Borneo Administrator. Kegiatan promosi dilakukan untuk lebih mengenalkan Jurnal Borneo Administrator kepada pengguna. Hal ini sebagai salah satu metode yang ditempuh untuk mengejar naskah masuk. Terlebih lagi pada saat Jurnal Borneo Administrator belum terakreditasi sangat membutuhkan banyak naskah. Setelah pengguna banyak memasukkan naskah maka naskah masuk hingga tahap in review pun melimpah.
Berdasarkan gambaran umum kepuasan pembaca, tingkat kepuasan ratarata tertinggi diberikan pada indikator terbit triwulan ( $3 x$ setahun) dengan skor rata-rata sebesar 3.79 pada level puas, diikuti indikator format dan konten secara keseluruhan dengan skor rata-rata sebesar 3.73 dengan level puas. Rata-rata terendah terlihat dalam indikator fasilitas akses, unduhan, bahasa, jumlah artikel, dan kolom dengan skor masing-masing sebesar 3.48 dan 3.61 pada level puas. Pada indikator penilaian kemanfaatan terhadap profesi dan peningkatan karier mendapatkan penilaian puas dari para responden dengan nilai 3.70. Bagi para pemangku jabatan fungsional atau penulis dengan profesi, seperti dosen, peneliti, analis kebijakan, dan lain-lain memiliki kewajiban menulis untuk memenuhi kewajiban angka kredit. Maka para penulis pun mempertimbangkan pengiriman karya ilmiah pada jurnal yang memiliki akreditasi atau tidak karena terdapat perbedaan angka kredit yang memengaruhi nilai jabatan profesi. Penulis yang memublikasikan karya ilmiah pada jurnal yang memiliki akreditasi memiliki poin angka kredit yang lebih tinggi sebagai syarat kenaikan pangkat jabatan bagi sebagian profesi. Hal tersebut berkaitan dengan akreditasi yang diberikan Kemenristek/Dikti, di mana indikator tersebut berada pada kategori puas.

Sesuai indikator kepuasan terhadap pelayanan yang diberikan, responden memberikan penilaian sebesar 3.70 atau berada pada kategori puas. Tim pengelola Jurnal Borneo Administrator telah melengkapi infografis terkait alur pemrosesan naskah yang masuk hingga proses publikasi. Hal tersebut sebagai suatu nilai tambah dan keterbukaan antara 
pengelola jurnal dengan penulis. Secara lengkap rata-rata skor indikator disajikan dalam tabel 1.

Jika peneliti membandingkan tingkat kepuasan pembaca jurnal berdasarkan latar belakang profesi, terlihat bahwa pada dasarnya tidak terdapat perbedaan yang signifikan. Di mana rata-rata pembaca dari latar belakang profesi yang berbeda menyatakan tingkat kepuasan pada level puas. Perbandingan tingkat kepuasan pembaca jurnal berdasarkan latar belakang profesi dapat terlihat dalam gambar 1 .

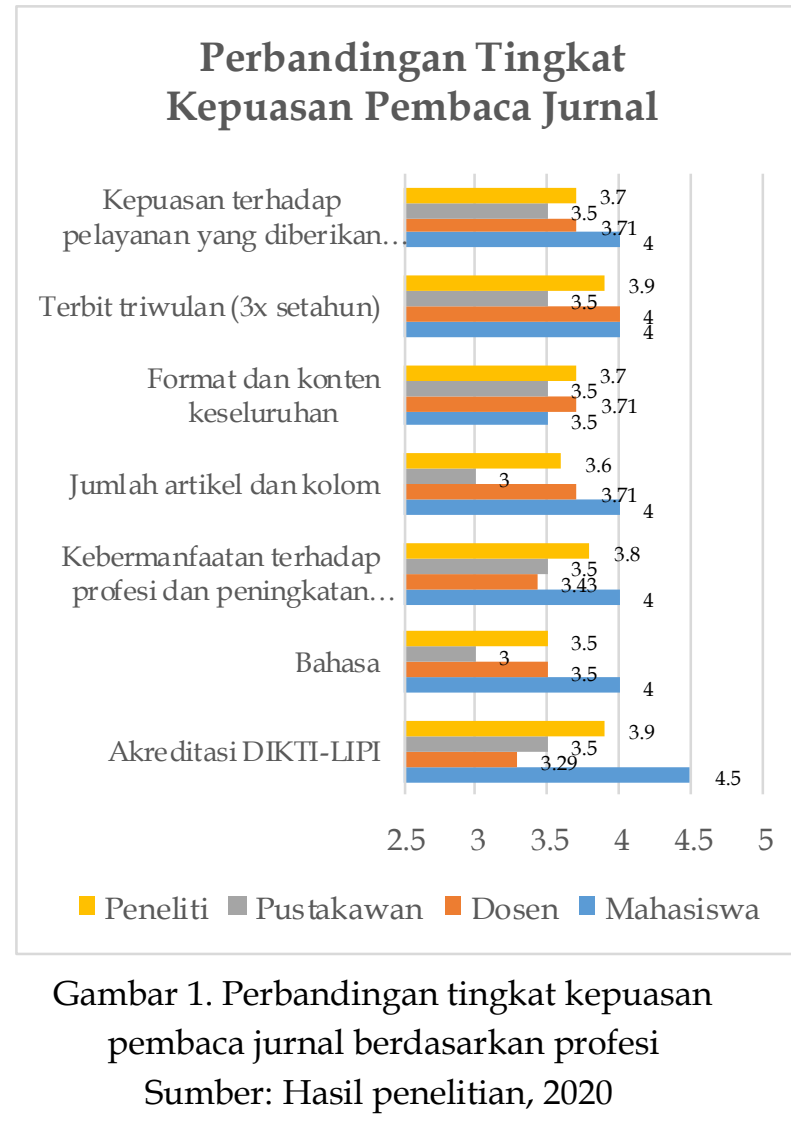

Sesuai temuan di atas, tingkat kepuasan pembaca terhadap beberapa indikator yang dinilai berada pada kategori puas. Bahkan pada pembaca kelompok mahasiswa, indikator fasilitas akses, unduhan, akreditasi, dan ranking dari Kemenristek/Dikti (Sinta) berada pada kategori sangat puas. Hal ini menarik apabila melihat unsur akreditasi
Kemenristek/Dikti pada Jurnal Borneo Administrator. Kemenristek/Dikti memberikan ranking pada setiap jurnal online melalui program Sinta yang digagas ternyata memberikan suatu kepuasan bagi pembaca maupun penulis. Bagi beberapa pemangku jabatan fungsional, menulis artikel dan memublikasikan di jurnal akreditasi akan mendapatkan nilai angka kredit yang lebih besar daripada jurnal yang belum akreditasi dan sebagai salah satu tolak ukur kepuasan pembaca maupun penulis.

Pada hasil penilaian pada tabel 1, didapatkan bahwa unsur kepuasan terhadap pelayanan yang diberikan pengelola selalu menempati peringkat terbawah, tetapi masih berada pada kategori puas. Pihak pengelola Jurnal Borneo Administrator menyikapi hal ini, bahwa pengelola telah menampilkan kontak pribadi dan email pengelola Jurnal Borneo Administrator agar setiap pertanyaan atau keluhan dapat dipantau dan ditindaklanjuti secara cepat. Berdasarkan temuan hasil survei kemanfaatan Jurnal Borneo Administrator secara online di rentang 2014-2016, capaian indeks kemanfaatan Jurnal Borneo Administrator pada 2016 meningkat dibandingkan tahun sebelumnya sebesar 2,8 menjadi 7,2 (Pusat Kajian dan Pendidikan dan Pelatihan Aparatur (PKP2A) III LAN, 2016). Mayoritas pengguna artikel Jurnal Borneo Administrator tidak banyak mengalami perubahan dibandingkan survei pada 2016 lalu, yaitu peneliti dan dosen yang memiliki kewajiban dalam penulisan karya tulis ilmiah.

Kemanfaatan Jurnal Borneo Administrator diukur menggunakan survei, akreditasi yang didapatkan dari Kemenristek/Dikti dengan Nomor 
21/E/KPT/2018 tertanggal 9 Juli 2018, dan jumlah kutipan yang digunakan. Semakin banyak suatu artikel yang disitasi penulis lain, maka kemanfaatan artikel tersebut akan semakin baik. Salah satu metode yang banyak digunakan pengelola jurnal untuk mengetahui jumlah kutipan melalui Google Scholar. Selain itu, Google Scholar digunakan Jurnal Borneo Administrator untuk mengukur kualitas jurnal. MartinMartin, Orduna-Malea, Harzing, \& LópezCózar (2017) dalam penelitiannya menemukan bahwa Google Scholar dapat digunakan untuk mengidentifikasi secara efektif terhadap dokumen atau artikel ilmiah yang telah dikutip penulis. Hal ini mengingat cakupan Google Scholar sangat luas. Sama halnya penelitian Breuer and Bowen (2014), yang menyatakan bahwa dampak ilmiah dari suatu karya tulis ilmiah diukur secara kasar menggunakan jumlah kutipan. Google telah lama menyediakan indeks terhadap publikasi ilmiah melalui Google Scholar dan fasilitas Google Books. Breuer and Bowen (2014) kembali menjelaskan bahwa Google Scholar memiliki koleksi data publikasi akademis/ilmiah yang lengkap dan terus memperbarui diri. Google Scholar sebagai fasilitas terdepan dalam penyediaan data kutipan artikel ilmiah. Adapun indeks sitasi tertinggi Jurnal Borneo Administrator (indeks- $h$ ) dengan skor 4, yang berarti terdapat 4 artikel yang mendapatkan indeks tertinggi sebanyak 4 sitasi (Pusat Kajian dan Pendidikan dan Pelatihan Aparatur (PKP2A) III LAN, 2017).

Sesuai Tabel 2, artikel Jurnal Borneo Administrator yang telah disitasi berjumlah 623. Adapun indeks sitasi tertinggi Jurnal Borneo Administrator (indeks-h) pada skor 11 yang artinya sebanyak 11 artikel mendapatkan indeks tertinggi sebanyak 11 sitasi yang meningkat dari tahun 2017. Berdasarkan data yang dirangkum pada Gambar 2, menunjukkan bahwa pemanfaatan artikel ilmiah Jurnal Borneo Administrator oleh peneliti lain. Pemanfaatan tersebut terlihat dari semakin meningkatnya jumlah kutipan pada artikel Jurnal Borneo Administrator. Salah satu kemanfaatan hasil penelitian suatu Karya Tulis Ilmiah (KTI) dapat dilihat dari banyaknya penulis yang melakukan sitasi KTI tersebut.

Tabel 3

Sitasi dan indeks Jurnal Borneo Administrator

\begin{tabular}{lll}
\hline Dikutip oleh & Semua & Sejak 2015 \\
\hline Kutipan & 623 & 589 \\
Indeks-h & 11 & 10 \\
Indeks-i10 & 14 & 13 \\
\hline
\end{tabular}

Sumber: Google Cendekia (2020)

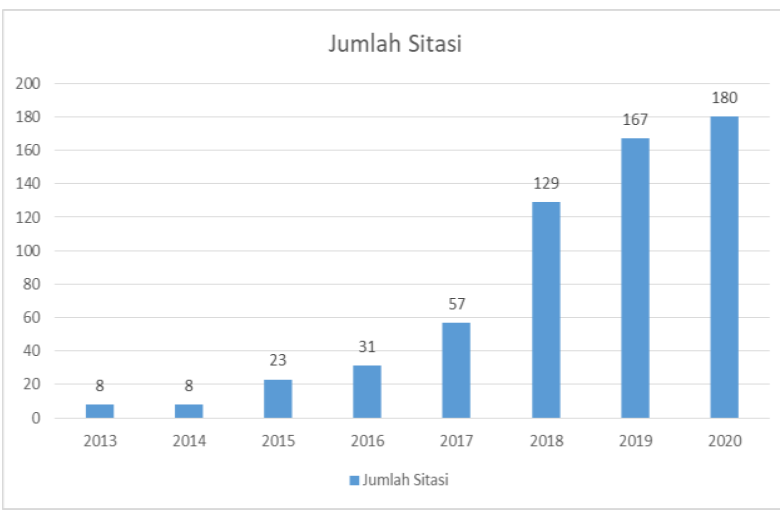

Gambar 2. Tingkat sitasi Jurnal Borneo Administrator 2013-2020

Sumber: Google Cendekia (2020)

Jurnal Borneo Administrator mendapatkan akreditasi peringkat Sinta 2 berdasarkan Kutipan dari Keputusan Direktur Jenderal Penguatan Riset dan Pengembangan, Kementerian Riset, Teknologi, dan Pendidikan Tinggi Republik Indonesia Nomor: 21/E/KPT/2018 Tentang Hasil Akreditasi Jurnal Ilmiah Periode I Tahun 2018. Akreditasi yang didapatkan Jurnal Borneo 
Administrator berlaku 5 (lima) tahun, yaitu Volume 12 Nomor 1 Tahun 2016 hingga Volume 16 Nomor 3 Tahun 2020. Apabila melihat pada gambar 2, maka akan terlihat bahwa pada saat Jurnal Borneo Administrator belum mendapatkan status terakreditasi, tepatnya pada 2013 sampai 2015 menunjukkan jumlah sitasi yang relatif rendah berada di rentang 8-23 jumlah sitasi per tahun. Hal ini berbeda terjadi ketika Jurnal Borneo Administrator telah mendapatkan akreditasi peringkat Sinta 2, bahwa terjadi kenaikan jumlah sitasi yang cukup tinggi. Tercatat pada 2016 telah terjadi peningkatan jumlah sitasi sebanyak 31 dan mengalami tren kenaikan hingga pada 2020 terdapat 180 jumlah sitasi per tahun. Jumlah sitasi telah digunakan sebagai indikator dampak ilmiah dari sebuah artikel/jurnal di banyak bidang (Davis, 2011).

Bukti pemanfaatan hasil penelitian oleh penulis lain dapat terlihat berdasarkan KTI yang dirujuk dalam hal penyusunan laporan hasil penelitian dan KTI yang diterbitkan pada jurnal ilmiah (Junandi, 2018). Suatu artikel yang memiliki jumlah sitasi banyak menandakan bahwa artikel tersebut memiliki daya tarik bagi perkembangan keilmuan tersebut. Tidak dapat dipungkiri bahwa pemanfaatan Google Scholar dewasa ini sangat membantu pengelola open access journal dalam mendapatkan gambaran nyata dari kemanfaatan dan dampak dari sebuah jurnal.

\section{SIMPULAN}

Kesimpulan dari penelitian ini, mayoritas responden adalah peneliti/cendekia dan dosen sebesar $66.7 \%$. Pengguna Jurnal Borneo Administrator melalui jurnal situs website dengan persentase sebesar $46.4 \%$ dan melalui teman/kolega sebesar $30.4 \%$. Ada 8 pertanyaan penelitian untuk mengukur tingkat kepuasan jurnal di antaranya, fasilitas akses dan unduhan, akreditasi Kemenristek/Dikti, bahasa, kemanfaatan terhadap profesi dan peningkatan karier, jumlah artikel dan kolom, format dan konten keseluruhan, dan terbit triwulan ( $3 x$ setahun) dan pelayanan yang diberikan pengelola JBA. Adapun tingkat kepuasan pembaca secara keseluruhan berada pada level puas, 3 indikator yang mendapatkan nilai tertinggi berdasarkan hasil survei berada pada indikator terbit triwulan ( $3 x$ setahun), format dan konten secara keseluruhan, dan kemanfaatan terhadap profesi dan peningkatan karier. Secara keseluruhan tingkat kepuasan pembaca berada dalam kategori puas, tetapi masih terdapat beberapa responden yang menjawab kurang puas pada indikator tingkat kepuasan terhadap terbit triwulan (3x setahun). Responden berada pada tingkat puas untuk bahasa, dan fasilitas akses dan unduhan. Berdasarkan keterbatasan penelitian ini, masih terbuka kemungkinan pengembangan riset ke depannya. Pengembangan penelitian selanjutnya berkaitan dengan penelitian yang telah dilakukan di antaranya kepuasan terhadap pelayanan pengelolaan jurnal yang diberikan pengelola dari beberapa jurnal berbasis open acces di lokus yang sama atau lintas lokus/daerah dan sebagainya. Peneliti mengingat tingkat pemanfaatan open acces journal yang masih belum optimal, maka pengembangan selanjutnya dapat menambahkan indikator penilaian kemanfaatan.

\section{DAFTAR PUSTAKA}

Al-Ali, M., Bazin, N. E. N., \& Shamsuddin, S. M. (2015). Key determinants of 
customer satisfaction: Evidence from Malaysia grocery stores. Journal of Theoretical and Applied Information Technology, 74(3), 286-299. Retrieved from

http:/ / www.jatit.org/volumes/Vol7 4No3/2Vol74No3.pdf

Azwar, M., \& Amalia, R. (2018). Pemanfaatan jurnal elektronik sebagai sumber referensi dalam penulisan skripsi di Institut Pertanian Bogor. LIBRARIA: Jurnal Perpustakaan, 5(1), 87.

https://doi.org/10.21043/libraria.v5i 1.2311

Breuer, P. T., \& Bowen, J. P. (2014). Empirical patterns in google scholar citation counts. Proceedings - IEEE 8th International Symposium on Service Oriented System Engineering, 398-403. Retrieved from

https://ieeexplore.ieee.org/documen t/6830937

Bruce, C., Davis, K., Hughes, H., Partridge, H., \& Stoodley, I. (2014). Information experience: Contemporary perspectives. In Library and Information Science: Vol. 9 (pp. 3-15). Emerald Group Publishing Limited. https:// doi.org/10.1108/S1876056220140000010001

Cakranegara, P. A., \& Susilowati, E. (2017). Analisis strategi implementasi media sosial: Studi kasus UKM “XYZ." Firm Journal of Management Studies, 2(2), 116. Retrieved from http://ejournal.president.ac.id/presunivojs/i ndex.php/FIRMJOURNAL/article/view/337/193

Davis, P. M. (2011). Open access, readership, citations: A Randomized controlled trial of scientific journal publishing. The FASEB Journal, 25(7), 2129-2134. https:/ / doi.org/10.1096/fj.11-183988

Đukić, S., \& Kijevčanin, V. (2012). Service quality as determinant of customer satisfaction. FACTA UNIVERSITATIS: Series: Economics and Organization, 9(3), 311-325. Retrieved from http://facta.junis.ni.ac.rs/eao/eao201 203/ eao201203-03.pdf

Google Cendekia. (2020). Jurnal Borneo Administrator (Google Scholar). Google Cendekia. Retrieved from https:/ /scholar.google.co.id/citations ?hl=id\&user=BvY6Hs8AAAAJ

Junandi, S. (2018). Keterpakaian dan relevansi Jurnal Agritech sebagai rujukan artikel jurnal ilmiah internasional terindeks Scopus. Jurnal Kajian Informasi \& Perpustakaan, 6(1), 95-108.

https:/ / doi.org/10.24198/jkip.v6i1.15 066

Kiramang, K. (2017). Perkembangan penerbitan jurnal open access dalam mendukung komunikasi ilmiah dan peranan perpustakaan. Pustakaloka: Jurnal Kajian Informasi Dan Perpustakaan, 9(2), 185-202. Retrieved form

http://jurnal.iainponorogo.ac.id/ind ex.php/pustakaloka/article/view/11 08/820

Laakso, M., \& Björk, B.-C. (2016). Hybrid open access-A longitudinal study. Journal of Informetrics, 10(4), 919-932. https://doi.org/10.1016/j.joi.2016.08. 002

Lewis, D. W. (2012). The Inevitability of open access. College $\mathcal{E}$ Research Libraries, 73(5), 493-506. Retrieved from

https:/ /crl.acrl.org/index.php/crl/ar ticle/view/16255/17701

Linuwih, S. N. (2015). Preferensi penggunaan jurnal ilmiah cetak dan non 
cetak: Studi deskriptif perilaku penemuan informasi di kalangan Dosen Universitas Airlangga (Skripsi) [Universitas Airlangga, Surabaya]. Retrieved form http://repository.unair.ac.id/17695/

Lukman, Marlina, E., Keumalasari, R., \& Siagian, A. H. A. M. (2012). Perkembangan open access jurnal ilmiah Indonesia. Prosiding Konferensi Perpustakaan Digital Indonesia (KPDI) Ke-5, 1-8.

https://doi.org/10.13140/2.1.1159.20 09

Martin-Martin, A., Orduna-Malea, E., Harzing, A.-W., \& López-Cózar, E. D. (2017). Can we use Google Scholar to identify highly-cited documents? Journal of Informetrics, 11(1), 152-163. https://doi.org/10.1016/j.joi.2016.11. 008

Peraturan Menteri Riset, Teknologi, dan Pendidikan Tinggi Republik Indonesia Nomor 9 Tahun 2018 Tentang Akreditasi Jurnal Ilmiah. 21 Maret 2018. Jakarta. Retrieved from https:/ / peraturan.bpk.go.id/Home/ Details/140402/permen-ristekdiktino-9-tahun-2018

Prasetyawan, Y. Y. (2017). Perkembangan open access dan kontribusinya bagi komunikasi ilmiah di Indonesia. Anuva: Jurnal Kajian Budaya, Perpustakaan, Dan Informasi, 1(2), 93 100.

https:/ / doi.org/10.14710/anuva.1.2.9 3-100

Purwadi, \& Irwansyah. (2020). Prospek dan tantangan industri penerbitan jurnal dan prosiding melalui teknologi e-publishing di era digital. BACA: Jurnal Dokumentasi Dan Informasi, 41(1), 87-98. https://doi.org/10.14203/j.baca.v41i1 .509
Pusat Kajian dan Pendidikan dan Pelatihan Aparatur (PKP2A) III LAN. (2016). Laporan Kinerja Lembaga Administrasi Negara (LKIP) Pusat Kajian dan Pendidikan dan Pelatihan Aparatur (PKP2A) III LAN 2016. Samarinda: Pusat Kajian dan Pendidikan dan Pelatihan Aparatur (PKP2A) III LAN.

Pusat Kajian dan Pendidikan dan Pelatihan Aparatur (PKP2A) III LAN. (2017). Laporan Kinerja Lembaga Administrasi Negara (LKIP) Pusat Kajian dan Pendidikan dan Pelatihan Aparatur (PKP2A) III LAN 2017. Samarinda: Pusat Kajian dan Pendidikan dan Pelatihan Aparatur (PKP2A) III LAN.

Sauber, P. (2013). Open access. The MIT Press. Retrieved from https://mitpress.mit.edu/books/ope n-access

Solomon, D. J., Laakso, M., \& Björk, B.-C. (2013). A longitudinal comparison of citation rates and growth among open access journals. Journal of Informetrics, 7(3), 642-650.

https://doi.org/10.1016/j.joi.2013.03. 008

Suwarno, W. (2014). Memperbincangkan penerapan open access untuk koleksi institusional repository. LIBRARIA: Jurnal Perpustakaan, 2(1), 14-28. Retrieved from

https://journal.iainkudus.ac.id/inde x.php/Libraria/article/view/1187/10 80

Thaotip, L., \& Nimnoi, R. (2013). Publishing of open access journal in Thailand. Procedia: Social and Behavioral Sciences, 73(4), 93-100. Retrieved from https://www.sciencedirect.com/jour nal/procedia-social-and-behavioral- 
sciences/vol/73/suppl/C

Wibowo, T. O. (2019). Strategi pengelolaan jurnal akses terbuka menggunakan Open Journal System (OJS). Berkala Ilmu Perpustakaan Dan Informasi, 5(1), 101-113.

https:/ / doi.org/10.22146/bip.38504

Young, J. S., \& Brandes, P. M. (2020). Green and gold open access citation and interdisciplinary advantage: A bibliometric study of two science journals. The Journal of Academic Librarianship, 46(2), 102-105. https://doi.org/10.1016/j.acalib.2019. 102105

Yudhanto, S., \& Nashihuddin, W. (2017).

Upaya pustakawan dalam peningkatan kualitas jurnal dan mendukung gerakan open access journal di Indonesia. Pustakaloka: Jurnal Kajian Informasi Dan Perpustakaan, 9(2), 283-311. Retrieved from

http://jurnal.iainponorogo.ac.id/ind ex.php/pustakaloka/article/view/10 90/919 


\section{DAFTAR TABEL}

Tabel 1

Perbandingan originality

\begin{tabular}{|c|c|c|c|}
\hline Penulis, judul, tahun & Kesamaan & Perbedaan & Kebaruan penelitian \\
\hline $\begin{array}{l}\text { Azwar and Amalia } \\
(2018)\end{array}$ & $\begin{array}{l}\text { Pemanfaatan artikel } \\
\text { jurnal ilmiah dalam } \\
\text { referensi merupakan } \\
\text { suatu hal yang baik. } \\
\text { Seperti yang diketahui } \\
\text { bahwa artikel ilmiah } \\
\text { yang diterbitkan } \\
\text { merupakan sumber } \\
\text { data primer }\end{array}$ & $\begin{array}{l}\text { Pemanfaatan jurnal } \\
\text { elektronik sebagai } \\
\text { bahan referensi relatif } \\
\text { tinggi di Institut } \\
\text { Pertanian Bogor (IPB). } \\
\text { Sebagian mahasiswa } \\
\text { telah memanfaatkan } \\
\text { jurnal elektronik sebagai } \\
\text { referensi dalam } \\
\text { penulisan skripsi }\end{array}$ & $\begin{array}{l}\text { Salah satu indikator } \\
\text { pengukuran survei } \\
\text { kepuasan pengguna } \\
\text { jurnal } \\
\text { adalah manfaat } \\
\text { terhadap profesi dan } \\
\text { karier }\end{array}$ \\
\hline $\begin{array}{l}\text { Bruce, Davis, Hughes, } \\
\text { Partridge \& Stoodley } \\
\text { (2014). Information } \\
\text { experience: Contemporary } \\
\text { perspectives }\end{array}$ & $\begin{array}{l}\text { Artikel open access } \\
\text { menerima lebih } \\
\text { banyak unduhan yang } \\
\text { signifikan, } \\
\text { meningkatkan jumlah } \\
\text { pembaca, dan mampu } \\
\text { menjangkau lebih } \\
\text { banyak khalayak luas } \\
\text { daripada artikel } \\
\text { dengan akses } \\
\text { berlangganan. Hal ini } \\
\text { mengarah pada } \\
\text { penyebaran } \\
\text { pengetahuan menjadi } \\
\text { lebih cepat }\end{array}$ & $\begin{array}{l}\text { Studi ini menjelaskan } \\
\text { bahwa artikel dengan } \\
\text { open access mendapatkan } \\
\text { lebih banyak hasil } \\
\text { unduh sehingga dapat } \\
\text { menjangkau khalayak } \\
\text { luas dalam tahun } \\
\text { pertama publikasi }\end{array}$ & $\begin{array}{l}\text { Penelitian ini mencoba } \\
\text { mengukur sejauh } \\
\text { mana kepuasan } \\
\text { pembaca terhadap } \\
\text { fasilitas akses dan } \\
\text { unduhan yang } \\
\text { dimiliki jurnal } \\
\text { berakses terbuka }\end{array}$ \\
\hline $\begin{array}{l}\text { Davis (2011). Access, } \\
\text { readership, citations: A } \\
\text { Randomized controlled } \\
\text { trial of scientific journal } \\
\text { publishing }\end{array}$ & $\begin{array}{l}\text { Artikel dengan open } \\
\text { access menerima hasil } \\
\text { unduh lebih banyak } \\
\text { dan secara signifikan } \\
\text { dapat menjangkau } \\
\text { audiens yang lebih } \\
\text { luas }\end{array}$ & $\begin{array}{l}\text { Studi ini meneliti terkait } \\
\text { perbandingan jumlah } \\
\text { hasil unduh dan } \\
\text { jangkauan artikel } \\
\text { kepada audiens dari } \\
\text { jurnal dengan open } \\
\text { access }\end{array}$ & $\begin{array}{l}\text { Penelitian ini mencoba } \\
\text { menilai kemanfaatan } \\
\text { jurnal open access } \\
\text { dengan melakukan } \\
\text { survei kepuasan } \\
\text { pengguna pelayanan. } \\
\text { Selain diukur melalui } \\
\text { open access, apakah } \\
\text { indikator akreditasi } \\
\text { sebuah jurnal dapat } \\
\text { menentukan jumlah } \\
\text { sitasi dari sebuah } \\
\text { artikel }\end{array}$ \\
\hline $\begin{array}{l}\text { Đukić, S., and } \\
\text { Kijevčanin (2012). } \\
\text { Service quality as } \\
\text { determinant of customer } \\
\text { satisfaction }\end{array}$ & $\begin{array}{l}\text { Kepuasan pengguna } \\
\text { pelayanan merupakan } \\
\text { tugas penting yang } \\
\text { diemban manajemen } \\
\text { (tim redaksi jurnal) } \\
\text { yang harus dicapai } \\
\text { karena menjadi } \\
\text { ukuran kesuksesan }\end{array}$ & $\begin{array}{l}\text { Studi ini menekankan } \\
\text { pada harapan } \\
\text { pengguna pelayanan } \\
\text { mengenai kualitas } \\
\text { pelayanan dan } \\
\text { komponen nilai lainnya } \\
\text { yang terus meningkat. } \\
\text { Penelitian ini mencoba }\end{array}$ & $\begin{array}{l}\text { Penelitian mengenai } \\
\text { kemanfaatan jurnal } \\
\text { dan evaluasi diri } \\
\text { pengelolaan jurnal } \\
\text { yang sangat jarang } \\
\text { ditemui karena } \\
\text { penelitian ini mencoba } \\
\text { memulainya }\end{array}$ \\
\hline
\end{tabular}




\begin{tabular}{|c|c|c|c|c|c|}
\hline $\begin{array}{l}\text { Thaotip and Nimnoi } \\
\text { (2013). Publishing of open } \\
\text { access journal in Thailand }\end{array}$ & $\begin{array}{l}\text { Penelitia } \\
\text { melakuk } \\
\text { kepuasar } \\
\text { pembaca } \\
\text { jurnal }\end{array}$ & $\begin{array}{l}\text { alam } \\
\text { si }\end{array}$ & $\begin{array}{l}\text { menerapka } \\
\text { pada kepua } \\
\text { pada Jurnal } \\
\text { Administra } \\
\text { Studi ini dil } \\
\text { terhadap ju } \\
\text { access di Th } \\
\text { lingkup ilm } \\
\text { perpustaka } \\
\text { informasi }\end{array}$ & $\begin{array}{l}\text { i } \\
\text { nulis } \\
\text { dalam } \\
\text { de }\end{array}$ & $\begin{array}{l}\text { Riset ini } \\
\text { kepuasa } \\
\text { pelayan } \\
\text { access di } \\
\text { dalam li } \\
\text { adminis }\end{array}$ \\
\hline \multicolumn{6}{|c|}{$\begin{array}{l}\text { Sumber: Azwar \& Amalia, 2018; Bruce, Davis, Hughes, Partridge, \& Stoodley, 2014; Davis } \\
\text { Kijevčanin, 2012; Thaotip \& Nimnoi, } 2013\end{array}$} \\
\hline \multicolumn{6}{|l|}{ Tabel 2} \\
\hline \multicolumn{2}{|l|}{ Item } & Mean & S.D & \multicolumn{2}{|l|}{ Level } \\
\hline \multicolumn{2}{|c|}{ Fasilitas akses dan unduhan } & 3.48 & 0.87 & Puas & \\
\hline \multicolumn{2}{|c|}{ Akreditasi Kemenristek/DIKTI } & 3.64 & 0.78 & Puas & \\
\hline \multicolumn{2}{|l|}{ Bahasa } & 3.61 & 0.83 & Puas & \\
\hline \multicolumn{2}{|c|}{$\begin{array}{l}\text { Kemanfaatan terhadap profesi dan } \\
\text { peningkatan karier }\end{array}$} & 3.70 & 0.73 & Puas & \\
\hline \multicolumn{2}{|l|}{ Jumlah artikel dan kolom } & 3.61 & 0.66 & Puas & \\
\hline \multicolumn{2}{|c|}{ Format dan konten keseluruhan } & 3.73 & 0.72 & Puas & \\
\hline \multicolumn{2}{|c|}{ Terbit triwulan ( $3 x$ setahun) } & 3.79 & 0.93 & Puas & \\
\hline \multicolumn{2}{|c|}{$\begin{array}{l}\text { Kepuasan terhadap pelayanan yang } \\
\text { diberikan pengelola }\end{array}$} & 3.70 & 0.73 & Puas & \\
\hline \multicolumn{2}{|l|}{ Total } & 29.26 & 6.25 & & \\
\hline
\end{tabular}

Sumber: Hasil penelitian, 2020 